\title{
Design and Implementation of computer Room Management System in University
}

\author{
Xuebin Jia \\ \{jiaxuebinwh@126.com\} \\ Department of Computer, Wuhan polytechnic Wuhan 430074, China
}

\begin{abstract}
At present, the number of computers in general university has more than 1000 , and the computer is distributed in the school room, now computer classes, many students in the use of time to study Internet chat, play games and watch movies etc.. And if the way the teacher inspection, has been unable to adapt to the current size of the room. In this paper, the system based on the needs of the actual functional requirements of the computer room management, using the relevant technology, developed a hierarchical model based on $\mathrm{B} / \mathrm{S}$ network monitoring management system. This system can be automated management system. Can greatly improve the management efficiency of the computer room, reduce the number of room management staff and improve work efficiency, but also can ensure that the computer room teaching resources are effective use of students. In this paper, the main work and achievements are as follows: firstly, this thesis research value and research background are introduced and of domestic and foreign scholars in the analysis, research results were detailed introduction; then the system key technology and system development required tool for the development of a simple introduction; according to the actual demand of our school computer room management, describes the system needed to achieve the function; in based on the functional requirements of the system, the completion of the design and implementation of the whole system. The system designed in this paper is suitable for the current network monitoring and management of college computer room, and solves the difficulty of the current computer room management, and improve the efficiency of the computer room.
\end{abstract}

Keywords: Computer room management; process monitoring; screen monitoring; remote control.

\section{Introduction}

With the rapid development of information technology and computer technology, the development of the computer room of the university is playing a more and more useful. In addition, in recent years, the cost of network equipment manufacturing is reduced, the network is widely used. In order to meet the needs of college students on the computer, at present, many colleges and universities have set up a number of computer room, computer room, a large number of computer. In order to more efficient management of college computer room, to strengthen the network management of the university computer room and network monitoring is becoming more and more important [1]. The purpose of network monitoring is to protect the computer room of the computer, so that it is more efficient to be used. At 
present, number and size of computer laboratory in Colleges and universities are in rapid growth, just rely on the increase in manpower and material resources monitoring and management, room management costs will be greatly increased, and the previous based on artificial management way, and indeed meet not currently in the management of computer room, computer room in colleges and universities urgently need new management model. The school has a computer room, a total of more than 500 computers. Although the use of hard disk card can protect the stability of the computer, but when the students on the plane, it is not good management. If you only use artificial methods to check, can not reach the expected results, the students in class to play games, a waste of computer resources in Colleges and universities. Therefore, at present, the effective management of university computer room is urgently needed. At present, there are a lot of problems in the computer room management in our school. In order to improve the existing management mode and improve the computer utilization rate, we have developed the network monitoring and management system. The system is based on the actual situation of our school's computer room to carry out functional requirements analysis, as well as the overall planning and design of the system [2].

Through its own network management software to monitor network equipment manufacturers, such as CISCO, H3C and other equipment manufacturers have specialized network management software. However, these manufacturers provide network management software is only to monitor the equipment provided by the manufacturer, not all devices are able to monitor, so the limitations of its use is too large. If it is the purchase of conventional network management software for the monitoring of the university computer room. The traditional network management system is deployed to a single system of the principle of work. Monitoring server and more than these restrictions, the user will not buy other products, for the installation of software in other servers. This is really necessary, set permissions and system forecast alarm values, etc.. This will certainly increase the system's manpower and material cost of the system. Monitoring is mainly in order to improve the efficiency of the use of computer room, if the use of traditional network management products in the university computer room, can not solve the current problems, but this will increase the complexity of the management room. Therefore, the traditional network management products can not meet the needs of the university computer room. At present, many users, such as the various portals, many game companies and telecommunications companies, etc., need to monitor the management system. Traditional computer room network and monitoring system can not meet such a large and medium-sized schools. In this regard, the timely introduction of the United States and the timely introduction of cloud management solutions, cloud network virtualization and cloud computing scalability, the right to apply to the quality of supervision and management approach, the perfect solution to the problem of large-scale monitoring. Its working principle can be summarized are as follows: monitoring is generally a single large monitoring and management server, the need to compute the ability, and stable operation, users early under the condition of low cost, existing a lot of equipment and network supervision and need to be monitored object dynamics and regulatory system change.

\section{System Related Technology Overview}

In the development of information management system, its structure is the key factor of the system. In recent years, with the rapid development of computer network technology, client / server and browser / server mode gradually become a kind of more advanced 
information management system development pattern, at present, C / S model has been widely used in many information management system development too in the process. This client / server and browser / server mode, both with high efficiency, easy to achieve large-scale distributed processing, etc.. At present, many information management system is developed using C/S structure. Only a few of these systems are developed using the three layer B/S structure. Therefore, the establishment of a good system architecture, should focus on the actual needs, the only way to achieve a reasonable and effective use of the client and server resources, and truly reflects the advanced system architecture.

\subsection{Database Development Tools}

Microsoft's Windows series server, coupled with its Server SQL, is already a very popular software development portfolio. Due to the SQL Server database is very powerful, and the operation is very simple, and the windows server operating system to close the seamless integration, the combination, each development will be preferred combined development tool. He not only supports the application of a good distributed system, but also the reliability is very good, can meet the actual needs of users. The SQL Server database engine is the process of relational data and provide the very good guarantee for structured data security, provide very good reliability for structured data storage function and, combination tools the system design and development personnel capable of very rapid construction and for the management of business data, and the availability and performance are very high. Therefore, in this context, the system uses the database for Microsoft's Server SQL [3].

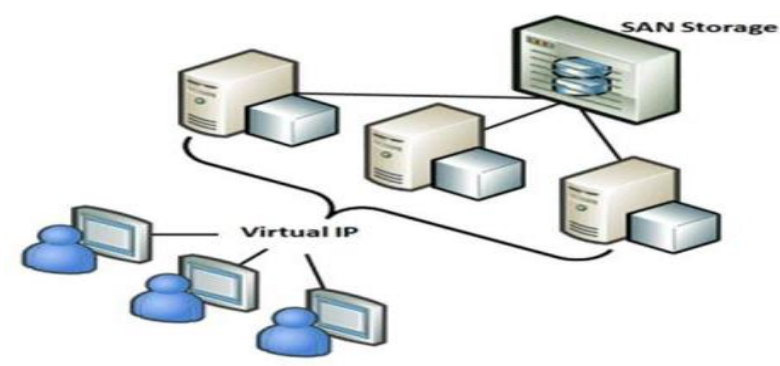

Fig. 1. Schematic diagram of Server SQL database

\section{$2.2 \mathrm{~B} / \mathrm{S}$ Structure Analysis}

$\mathrm{B} / \mathrm{S}$ structure, which is the browser / server structure, is widely used because of its good scalability. System through the use of B/S architecture to build, all users of the system can be accessed through the browser on the system. In this architecture, the part of the system has been implemented at the front end of the system, while in the server's back end, it will focus on the implementation of the other tasks of the system. B/S this way of access, to a large extent reduces the requirements of the customer access system, as long as the user has a browser to achieve the system's access. This architecture, but also reduced the system developed after the system for system maintenance and system upgrades brought about by the enormous consumption. B/S architecture to achieve a one-time development, at the same time, this architecture can also make different places, different ways of working, as well as a variety of personnel, are able to access the system. Therefore, based on the B/S system, the maintenance and upgrade of the system is relatively simple. Therefore, due to the above 
advantages [4], $\mathrm{B} / \mathrm{S}$ architecture is used by more and more people, and its working principle is shown in Fig. 2:

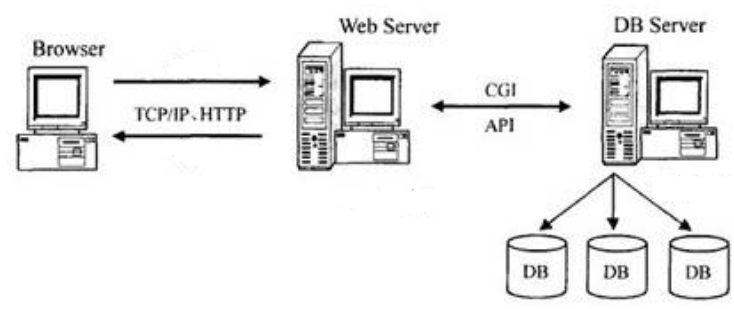

Fig. 2. Schematic diagram of $B / S$ mode

\subsection{MVC Development Framework}

MVC is the abbreviation of model view controller, which mainly includes model layer, view layer and controller layer. In the architecture, system control layer to layer model of business function code and the view layer of the display part of the code and effective isolation using, so as to improve the level of system module and also reduces the complexity of maintenance system, to make the model view control framework developed code is easy to maintain.

\section{System Design and Implementation}

So-called system management module's function is the basic operation of the management system; database module function is to preserve the system information, such as user login information, monitoring information; data analysis module is mainly to the system data for analysis and extraction, and will have the effect of information is provided to the system administrator; system monitoring module mainly on students' online behavior of realtime monitoring, and real-time display and record the operation of monitoring; room management module mainly to the engine room management, such as room management download speed, student management machine behavior. The monitoring module is one of the core modules of the system, and the functional design of all the core parts of the system is also concentrated in this module. In this paper, we use the programming method based on Windows system, programming method based on network technology, and image transmission and storage method based on video compression coding and decoding. Student online monitoring system is mainly to monitor students in room Internet access behavior, mainly including student login into the computer system operation of computer for processing and operation, and also includes the obtained by monitoring system of the video image in real time [5].

Computer terminals on the computer to install monitoring and management procedures, and provide relevant regulatory services. Related attributes: local service: as a non privileged user, the local computer account to take action, which will provide anonymous credentials to any remote server; local system: a senior privileges account; service network: the system needs to provides a very wide range of feasible this privilege account. Account member specifies the user, which causes the system prompt to enter a valid user name and password for the installation service. This system needs to set up the self protection function for the computer program in the process of student's computer. The main purpose of setting this 
function is: some students in the course of the machine, the system may shut down the regulatory process. In order to prevent the students in the process of illegal on the system to monitor the process of closing the system, the system set up the function of self protection. There are two ways to protect the function of the system, the first one is the procedure, the second is the non procedural mode. This system in order to realize the function of selfprotection. First, the system will through the program to modify the service provides attributes. Then, on the basis of this, system will go through non procedural means to achieve the parameters of the system are set.

\section{Conclusion}

This paper completed the university computer room management system needs analysis, system architecture design, system detailed design and system implementation, system test and so on. In the system requirements analysis stage, the article from the system administrators, students, computer room teacher's point of view of the system of the behavior of a more detailed analysis, and gives the system use case diagram. System architecture design is the core task in the development of the system, in this paper, the classical model of threetier architecture, in the architectural design process, the article pays more attention to the reuse of the flexibility of the framework and architecture level functional modules, such as in the system, system administrators, students, teachers password modified function module is a functional module. System design and implementation process, based on the needs analysis and architecture design, the function of the system to carry out a more detailed design, and carry out specific implementation. Because of the function of the system, this paper in the system detailed design and the realization process of spent more time, through long time efforts, this paper realizes the pre needs analysis in all functional and non functional requirements. After the design and implementation of the system, all the functions of the system are realized, and a comprehensive test is done. The system can meet the actual needs.

\section{References}

[1] In Ying. Online examination system based on JSP and Oracle design and implementation of. computer programming skills and maintenance. No. 04. (2013)

[2] Zhong Wenxiang. Design and implementation of. information and computer based on Web educational administration system (theoretical Edition). No. 01. (2013)

[3] What Yijian. Struts framework MVC application of. computer knowledge and technology based on. No. 13. (2010)

[4] History of the. Based on the JSP academic management system design. Journal of Changchun University of Technology (NATURAL SCIENCE EDITION). No. 03. (2014)

[5] Liao Xinbin. The management and maintenance of the computer room in Colleges and universities. Journal of Jiujiang Vocational and Technical College. No. 04. (2012) 